\title{
Effect of prenatal cocaine on early postnatal thermoregulation and ultrasonic vocalization production
}

\author{
Matthew S. McMurray ${ }^{*}{ }^{*}$ Philip S. Zeskind ${ }^{2}$, Stephanie M. Meiners ${ }^{3}$, Kristin A. Garber $^{2}$, Hsiao Tien $^{4}$ \\ and Josephine M. Johns ${ }^{3}$
}

${ }^{1}$ Department of Psychology, University of Illinois at Chicago, Chicago, IL, USA

2 Department of Pediatrics, Levine Children's Hospital at Carolinas Medical Center, Charlotte, NC, USA

${ }^{3}$ Department of Psychiatry, University of North Carolina, Chapel Hill, NC, USA

${ }^{4}$ Frank Porter Graham Child Development Institute, University of North Carolina, Chapel Hill, NC, USA

\section{Edited by:}

Femke Buisman-Pijlman, The

University of Adelaide, Australia

Reviewed by:

Stefan Brudzynski, Brock University,

Canada

Emily J. Jaehne, University of

Adelaide, Australia

*Correspondence:

Matthew S. McMurray, Department of Psychology, University of Illinois at Chicago, 1007 W Harrison St. M/C 285, Chicago, IL 60607, USA e-mail:mcmurray@uic.edu
Prenatal cocaine exposure can alter the postnatal care received by rat pups. Such effects could be caused in part by alterations in pup-produced stimuli that elicit early postnatal maternal care. Pup ultrasonic vocalizations are thought to be a particularly salient stimulus, and when paired with other cues, may elicit maternal attention. Cocaine is known to acutely alter thermoregulatory and cardiac function, thus prenatal cocaine may affect vocalizations through altering these functions. The data presented here determine the impact of full term prenatal cocaine exposure, saline exposure, or no exposure on thermogenic capacity, cardiac function, and the resulting ultrasonic vocalizations across the early postnatal period (days 1-5). Results indicated that while sharing many similar characteristics with saline-exposed and untreated animals, prenatal cocaine exposure was associated with specific alterations in vocalization characteristics on postnatal day 1 (PND 1), including call amplitude. Furthermore, numerous spectral parameters of their vocalizations were found altered on PND 3, including rate, call duration, and frequency, while no alterations were found on PND 5. Additionally, cocaine-exposed pups also showed a reduced thermoregulatory capacity compared to saline animals and reduced cardiac mass compared to untreated animals on PND 5. Together, these findings indicate that prenatal cocaine may be altering the elicitation of maternal care through its impact on vocalizations and thermoregulation, and suggests a potential mechanism for these effects through cocaine's impact on developing stress systems.

Keywords: prenatal cocaine, thermogenesis, ultrasonic vocalization, cardiac, brown adipose tissue, stress

\section{INTRODUCTION}

Unlike the profound neuroanatomical and behavioral alterations associated with Fetal Alcohol Spectrum Disorder (Kodituwakku, 2009; Norman et al., 2009), those associated with prenatal cocaine exposure are more subtle. These effects are well-documented (Chae and Covington, 2009; Bandstra et al., 2010) and a number may directly impact the ability of the infant to elicit optimal maternal care. Deleterious effects of cocaine exposure on maternal stress responsivity and infant attention have been reported in human clinical populations (Strathearn and Mayes, 2010), as well as in studies of rodent mothers treated with cocaine while pregnant (Kinsley et al., 1994; Vernotica et al., 1996, 1999; Quiñones-Jenab et al., 1997; Johns et al., 1998, 2005; Nelson et al., 1998; McMurray et al., 2008). While there is currently a rich literature demonstrating the effects of cocaine on rodent maternal behaviors, few studies to date have systematically examined how cocaine alters auditory, olfactory, and other stimuli produced by pups that elicit care.

A number of cues produced by infants can modify maternal responses, including ultrasonic vocalizations (USVs) (Smotherman et al., 1974; Brunelli et al., 1994; Farrell and Alberts, 2002a,b; D’Amato et al., 2005; Okabe et al., 2013), odors (Lévy et al., 2004; Okabe et al., 2013), and temperature (Henning and
Romano, 1982; Bates et al., 1985; Leon et al., 1985; Adels and Leon, 1986; Woodside and Jans, 1988; Jans and Woodside, 1990; Stern and Lonstein, 1996). The importance of each cue depends to varying extents on the maternal environment, age of the pup producing the cue, and numerous other factors (Champagne et al., 2001, 2003; Mattson et al., 2001; Brudzynski, 2005). Additionally, pup-produced cues likely interact with alterations in maternal perception and response resulting from drug exposure or environmental disruption. As a stimulus for maternal attention, a sustained high-rate of vocalizing by pups is the most effective for eliciting retrieval from dams (Deviterne et al., 1990; Brunelli et al., 1994; Farrell and Alberts, 2002a,b; Zimmerberg et al., 2003; Fu et al., 2007) and can also be an important stimulus for licking (Brouette-Lahlou et al., 1992), an important social behavior. Rats of various ages vocalize in response to handling, cold temperatures, isolation, and social factors (Blumberg et al., 1992; Shair et al., 1997; Branchi et al., 2001; Hahn and Lavooy, 2005); thus, USVs constitute one avenue of communication between pup and mother (Brunelli et al., 1994; Brudzynski, 2005).

Aside from vocalizations, thermoregulation is also an important determinant of maternal attention. Decreases in pup body temperature have been associated with increases in nursing behaviors in rat dams, through which heat is passed to the litter 
(Henning and Romano, 1982; Bates et al., 1985; Leon et al., 1985; Adels and Leon, 1986; Woodside and Jans, 1988; Jans and Woodside, 1990; Stern and Lonstein, 1996). In the early postnatal period, individual rat pups rely not only on internal metabolic sources for heat production, but also on external sources, such as their littermates and their mother. As a litter, rat pups achieve warmth through huddling, are insulated from cold by the nest, and receive additional heat from their mother during close contact nursing. Isolated rat pups produce heat primarily through brown adipose tissue (BAT) thermogenesis (Smith, 1964; Alberts, 1978), supported by modulation of cardiorespiratory responses (Blumberg et al., 1997). Brown adipose tissue thermogenesis is immediately apparent at birth in rats (Blumberg et al., 1997; Sokoloff et al., 1998), and its disruption may play a role in the development of obesity and diabetes (Cinti, 2006, 2005; Cypess et al., 2009).

Thermal state also has tremendous influence over vocalizing behavior in early life. Aside from emotional and social factors, it has been hypothesized that many USVs produced in the early postnatal period are by-products of mechanisms that sustain cardiorespiratory function (Blumberg and Alberts, 1990; Blumberg and Sokoloff, 2001). Interestingly, such vocalizations do not depend on cortical control (Middlemis-Brown et al., 2005), suggesting that they may be independent from stress-induced vocalizations. It is unknown if characteristics (other than rate) of pup USVs are altered by increasing thermal challenges, although such relationships likely exist given the association between body weight and USV frequency (Blumberg et al., 2000). Regardless, these developmental changes in thermoregulation and vocalizations provide interesting targets of study for investigations of developmental disorders.

The effects of prenatal cocaine exposure on the relationship between pup thermal control, vocalization production, and cardiac function has not been thoroughly investigated. Prenatal cocaine likely alters thermally induced vocalizations through its impact on central serotonin (Ray et al., 2011) and norepinephrine (Madden et al., 2013), metabolism and cardiac rate (Blumberg et al., 1997; Sokoloff et al., 1998), and the developing stress response systems (Yee et al., 2011); all of which independently alter thermoregulation and vocalizations. Additionally, maternal cocaine use has been strongly associated with malnourishment of the mother and fetus, as well as placental vasoconstriction, which further complicates nourishment delivery to the fetus, potentially altering long-term adipose tissue volume and function (Mostyn and Symonds, 2009).

This study aimed to determine if there are differences in thermoregulation, cardiac function, and ultrasonic vocalization production resulting from prenatal cocaine exposure. Additionally, in normal animals decreased body temperature results in increased cardiac rate and vocalization production. Thus, an additional aim of this study was to determine if this normal relationship between these variables is intact following prenatal cocaine exposure. While these effects may have implications on maternal care, that endpoint is not studied here. Given cocaine's effects on thermoregulation in adults, we anticipated disregulation of thermoregulatory processes (including cardiac rate) across the postpartum period, resulting in alterations to the rate of vocalization and potentially more detailed acoustic characteristics (e.g., frequency or amplitude).

\section{METHODS \\ BREEDING}

This study was carried out in strict accordance with the recommendations in the Guide for the Care and Use of Laboratory Animals of the National Institutes of Health. The protocol was approved by the Institutional Animal Care and Use Committee at the University of North Carolina. All efforts were made to minimize suffering throughout the experiment.

Individually housed Sprague-Dawley nulliparous female rats (200 grams, Charles River, Raleigh, NC) were kept on a 12:12 reverse light cycle (8:00 AM dark) for 1 week and then mated until conception was noted by the presence of a vaginal plug and sperm in a vaginal smear (gestation day (GD) 0). Following conception, females were randomly assigned to cocaine, saline, or untreated groups as they became pregnant (see below for treatment information). Weight gain was measured daily for all animals throughout gestation. Water and chow was available ad libitum for all except saline-treated rat dams, who were matched with a cocaine dam on a pair-feeding schedule to control for any effects of cocaine-induced anorexia. Seven days following conception (GD 7), females were moved to a colony room and individually housed on a regular 12:12 light:dark cycle with lights on at 7:00 AM. This procedure results in the majority of dams delivering in the normal daylight hours (Mayer and Rosenblatt, 1998). PPD 1 was defined as the calendar day during which delivery was completed. Following delivery, litters were culled to 10 pups ( 5 males, 5 females) and pups were returned to their own biological mothers.

\section{DAM TREATMENT}

Females were randomly assigned to cocaine, saline, or untreated groups as they became pregnant. Cocaine-treated dams received twice-daily subcutaneous injections of $15 \mathrm{mg} / \mathrm{kg}$ of cocaine hydrochloride (calculated as free base, $1 \mathrm{ml} / \mathrm{kg} /$ injection total volume, Sigma, St. Louis, MO) dissolved in normal $(0.9 \%)$ saline at approximately 9:00 AM and 4:00 PM throughout gestation (GD 1-20) and not thereafter. Saline-treated dams received twice-daily subcutaneous injections of $0.9 \%$ Saline solution $(1 \mathrm{ml} / \mathrm{kg} /$ injection). To prevent skin lesions, injections were alternated daily between rear leg flanks. If a lesion appeared, the fur was clipped at the site, cleaned daily with a betadine solution, and a topical antibacterial ointment (Polymycin-BacitracinNeomycin, E. Fougera \& Co., Melville, NY) was applied to the area. These measures have been shown to minimize skin lesion appearance and severity (McMurray et al., 2008). Untreated control dams received no drug treatment or food restriction during gestation or during the postpartum period, but were weighed daily to control for the effects of handling.

\section{APPARATUS, TEMPERATURE MEASUREMENT, AND VOCALIZATION RECORDING}

The apparatus (depicted in Figure 1) consisted of a double-walled glass chamber described previously (Blumberg and Alberts, 1990; Blumberg and Stolba, 1996). Temperature-controlled water was 


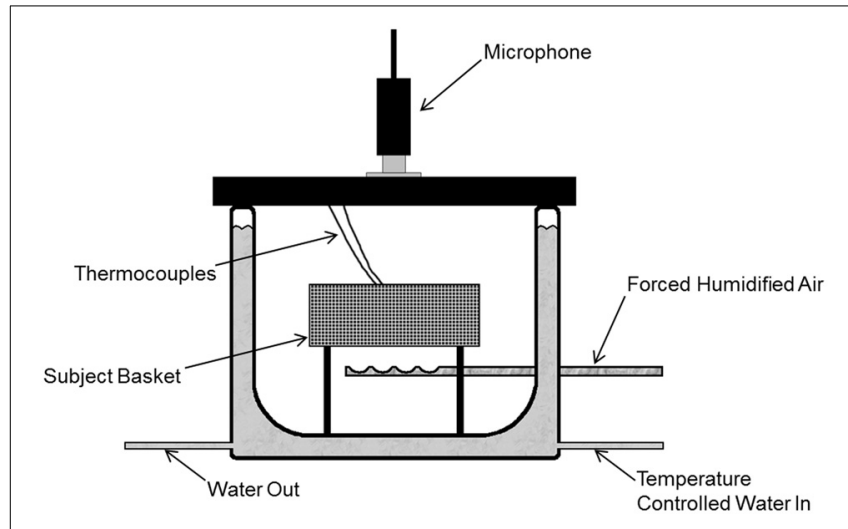

FIGURE 1 | The thermogenesis testing apparatus. The subject is placed in the subject basket inside the double-walled glass chamber. The walls of the chamber are filled with temperature-controlled water, which actively regulates the internal temperature of the chamber. Forced humidified air is pumped into the chamber throughout testing. Subject and ambient temperatures were measured using thermocouples.

pumped between the walls to control the internal chamber air temperature with a high degree of accuracy. Pups were placed in the chamber on a raised platform constructed of polyethylene mesh, a surface that is only weakly heat conductive and allows for the free passage of air through the chamber. Forced humidified air $(300 \mathrm{ml} / \mathrm{min})$ entered the bottom of the chamber, flowed past the pup, and exited through the lid. A mesh wall surrounded the platform to prevent pups from touching the chamber walls directly. Thus, the majority of heat loss by the pup would be convective and less rapid in nature. Holes in the side of the chamber, as well as in its plastic lid, allowed for the connection of thermocouples. Thermocouple leads for measuring physiological and air temperatures were attached to a National Instruments data acquisition device (USB-9211A), which sampled once per second per channel. All hardware and timing was controlled through LabView 2009 software.

Chamber air temperature $\left(T_{\mathrm{A}}\right)$ and physiological temperatures were measured using Chromel-Constantan (T-Type) thermocouples (OMEGA Engineering, Inc.; Stamford, CT). $T_{\mathrm{A}}$ within the metabolic chamber was measured using a thermocouple suspended $2 \mathrm{~cm}$ beneath the subject. Two physiological temperatures were acquired by attaching thermocouples just under the surface of the skin using callodion as an adhesive (Spiers and Adair, 1986; Blumberg and Stolba, 1996). One thermocouple was attached in the interscapular region above the brown fat pad, thus providing a measure of interscapular temperature $\left(T_{\mathrm{IS}}\right)$ and BAT thermogenesis. The other thermocouple was attached in the lumbar region, and measured the temperature of the back of the subject $\left(T_{\text {Back }}\right)$, a non-heat-producing region indicative of general body temperature. The difference between $T_{\mathrm{IS}}$ and $T_{\text {Back }}\left(T_{\mathrm{IS}}-T_{\text {Back }}\right)$ was used to confirm the presence and degree of brown adipose tissue thermogenesis (Hull and Segall, 1965; Blumberg and Stolba, 1996).

Ultrasonic recording equipment included model CM16/CMPA40-5V microphones (Avisoft Bioacoustics; Berlin, Germany) connected to a desktop computer through a National
Instruments instrumentation recorder (PCI-6132). Microphone voltage was sampled at a rate of $1 \mathrm{MS} / \mathrm{s}$ ( 1 million samples per second) at 14 bit, which allowed for high fidelity recording at frequencies well beyond $100 \mathrm{kHz}$, more than double the expected fundamental frequency range of $40-50 \mathrm{kHz}$. Microphones were calibrated prior to each use with the Calibration Unit for Recording Transducers (McMurray and Hubbard, 2013). National Instruments software (LabView, 2009) began acquisition of ultrasonic vocalizations at the session start and terminated at the session end as described below. Recordings were conducted within the thermoregulatory test chambers described above.

\section{TESTING PROCEDURE}

On PNDs 1, 3, and 5, one pup of each sex with a visible milk band was removed from the litter, weighed, and placed onto a $36^{\circ} \mathrm{C}$ heat pad for transit to either the testing apparatus (PND 1) or surgical space (PND 3 and 5). To ensure the same pups were not retested at a later developmental time point, they were marked with paw tattoos following testing. Since rat pups exhibit agedependent thermogenic capacities (Blumberg and Stolba, 1996), age-appropriate thermal challenges were used. Due to the fragile nature of pups on PND 1, thermogenesis was not measured on this day. However, considering the relationship between temperature and vocalization production at this age, a thermal challenge is necessary for the elicitation of vocalizations; thus, pups on this day were rapidly chilled by placing them on a $25^{\circ} \mathrm{C}$ metal plate for $5 \mathrm{~min}$, during which vocalizations were recorded continuously. Following this, the pup was returned to the incubator and transported back to its litter.

Across PNDs 3 and 5, pups develop greater thermogenic capacity. Thus, the measurement of thermogenesis becomes relevant and is accomplished via implantable thermocouples. Each pup was anesthetized with isoflurane (5\% for induction, $2 \%$ for maintenance), thermocouples were implanted 1-2 mm under the skin, and pups were promptly returned to the transportation incubator. This procedure was completed in less than $5 \mathrm{~min}$ and subjects were maintained at thermoneutral temperatures throughout surgery using heat pads. After surgery, subjects were transported in the incubator to the test room and placed into the thermal chambers. Data collection began following $60 \mathrm{~min}$ of habituation to the chamber at thermoneutral temperatures and continued for $2 \mathrm{~h}$ using a series of thermal challenges. Variations in the thermogenic capacities of PND 3 and 5 pups (Blumberg and Stolba, 1996) required the use of age-appropriate thermal challenges (detailed in Figure 2). On PND 3, after $60 \mathrm{~min}$ of habituation at $36.0^{\circ} \mathrm{C}$, the environmental temperature $\left(T_{\mathrm{E}}\right)$ within the apparatus was reduced to $32.0^{\circ} \mathrm{C}$ (a moderate temperature challenge) for another $60 \mathrm{~min}$, and then again reduced to $28.5^{\circ} \mathrm{C}$ (an extreme temperature challenge) for a final $60 \mathrm{~min}$. On PND 5, pups were treated in the same manner, except that the habituation temperature was held at $35.0^{\circ} \mathrm{C}$, the moderate temperature challenge was $28.0^{\circ} \mathrm{C}$, and the extreme temperature challenge was $21.0^{\circ} \mathrm{C}$. Biometric data were collected and vocalizations recorded continuously during the tests. Following testing, pups were returned to their litters. The final number of pups tested was 14 cocaine-exposed, 15 saline-exposed, and 17 untreated on PND 1; 30 cocaine-exposed, 28 saline-exposed, and 31 untreated 


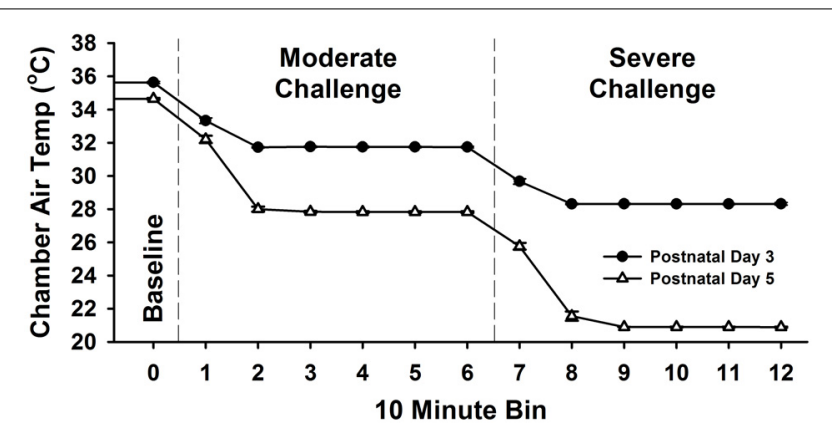

FIGURE 2 | Environmental challenges posed on postnatal days (PND) 3 and 5. Subjects were first exposed to a baseline thermoneutral habituation period for $1 \mathrm{~h}\left(\mathrm{PND} 3: 36^{\circ} \mathrm{C}\right.$, PND 5: $35^{\circ} \mathrm{C}$ ), then a developmentally appropriate moderate thermal challenge for $1 \mathrm{~h}$ (PND 3: $32^{\circ} \mathrm{C}$, PND 5: $28^{\circ} \mathrm{C}$ ), and lastly an extreme thermal challenge for $1 \mathrm{~h}$ (PND 3: $28.5^{\circ} \mathrm{C}$, PND 5: $\left.21^{\circ} \mathrm{C}\right)$.

on PND 3; and 31 cocaine-exposed, 34 saline-exposed, and 31 untreated on PND 5.

\section{CARDIAC FUNCTION ASSESSMENT}

In a separate group of PND 5 animals treated identically to those described above (cocaine and untreated animals only, 10 males and 10 females per group), cardiac function was assessed during the same thermal test. This was done in a separate group of animals, and USVs were not recorded during this experiment. No saline animals were included in this experiment, since they did not differ from cocaine in their thermoregulatory or vocalization responses at this age. Electrocardiograph (ECG) probes (Model 2330, 3M; St. Paul, MN) were applied to the pup's thoracic region, on either side of the interscapular region, with a ground probe applied to the rump region. The data were visually displayed in real-time using an oscilloscope, recorded to the computer via National Instruments hardware (USB-6210), and analyzed to determine average heart rate and R-R intervals from the QRS complex (LabView, 2009). After the test, pups were removed from the chamber and cardiac tissue extracted. After unanaesthetized decapitation, a thoracic incision was made and the heart was removed, keeping intact the atria and ventricles. After collection, cardiac tissue samples were immediately weighed and frozen at $-81^{\circ} \mathrm{C}$ until time of assay. In order to obtain sufficient tissue for $\beta$-adrenergic receptor quantification, cardiac tissue was collected from all subjects, as well as for their eight untested littermates.

\section{$\beta$-Adrenergic receptor quantification}

Dissected cardiac tissue was stored at $-80^{\circ} \mathrm{C}$ until assayed for $\beta$-adrenergic receptor $(\beta \mathrm{AR})$ levels using a radiolabeled binding assay, as described previously (Mason et al., 1987, 1993). Tissue from four males or four females per group was pooled to obtain sufficient tissue for measurement. A membrane fraction was prepared from heart tissue by homogenization in 6 vol $0.32 \mathrm{M}$ sucrose in $40 \mathrm{mM}$ Tris- $\mathrm{HCl}$ buffer ( $\mathrm{pH} 7.4)$ containing $10 \mathrm{mM}$ $\mathrm{MgCl} 2$ and then centrifuged at $900 \mathrm{~g}$ for $10 \mathrm{~min}$. The supernatant was spun at $48000 \mathrm{~g}$ for $10 \mathrm{~min}$. The pellet was washed twice in
$40 \mathrm{mM}$ Tris/ $\mathrm{MgCl} 2$ buffer by rehomogenization and recentrifugation to produce the final $\mathrm{P} 2$ fraction pellet. For the $3 \mathrm{H}-\mathrm{DHA}$ binding assay (relatively equal binding affinities for $\beta 1$ and $\beta 2$ receptor subtypes), an aliquot of the tissue was prepared and resuspended in $40 \mathrm{mM}$ TRIS/MgCl 2 buffer at a concentration of about $166 \mathrm{mg}$ of the original tissue/ml. These assay incubations were done in triplicate in $1 \mathrm{ml}$ medium containing $40 \mathrm{mM}$ TRIS$\mathrm{HCl} / 10 \mathrm{mM} \mathrm{MgCl} 2 \mathrm{pH} 7.4$ and $2 \mathrm{nM} 3 \mathrm{H}-\mathrm{DHA}$ (41.2 Ci/mmol). After the $25 \mathrm{~min}$ incubation period at $25^{\circ} \mathrm{C}$, samples were filtered on glass fiber discs ( 0.45 micron pore size, Gelman Inc., Ann Arbor, MI) and washed twice quickly with $5 \mathrm{ml} \mathrm{TRIS/MgCl} 2$ buffer. These discs were dried and counted in $5 \mathrm{ml}$ ScintiSafe scintillation mixture with a Beckman LS 7000 scintillation counter at an efficiency of $63 \%$. Non-specific binding was measured using a competing unlabeled ligand (10-6 M propranolol). Due to the very limited amount of heart tissue per animal, pooled tissue was assayed at a single $3 \mathrm{H}$ DHA concentration of $2 \mathrm{nM}$. Since no significant differences were seen at this concentration near the Kd value, scatchard type analysis was not performed. Single point data were used to compare mean receptor binding between treatment groups.

\section{DATA ANALYSIS}

Although males and females typically had different body weights, after including weight in our statistical models, no consistent sex differences were apparent in temperature or vocalization production. Therefore, males and females were combined into a single group.

Linear mixed models accounting for the clustering of pups coming from the same dam were used to compare the repeated measures of gestational data and subject body weight. $T_{\mathrm{IS}}, T_{\mathrm{Back}}$, and $T_{\mathrm{IS}}-T_{\mathrm{Back}}$ data were binned into 10 -min intervals for statistical and presentation purposes, and for comparisons between treatment groups and sexes. No statistical comparisons between PND 3 and 5 could be made, because of the different ageappropriate thermal challenges used for each time point. To reduce the total number of statistical comparisons, the focus of our analysis was on temperatures from the two thermal challenges. Thus, data from the first $50 \mathrm{~min}$ of unchallenged thermal habituation were excluded from our statistical models. Data from the last 10-min bin of the habituation period was included in figures as an estimate of baseline temperature. Remaining data are presented as change from baseline temperature. Means and standard deviations are presented in figures, and while all data are discussed in text, only treatment-specific data are presented in figures.

The ultrasonic vocalization measures analyzed included likelihood to call, number of vocalizations produced, and duration of each call. Additionally, acoustic spectral properties were examined, including measures of pitch (highest and lowest frequency achieved by the fundamental frequency), acoustic power (maximum amplitude), number of harmonics visible (additional waveforms visible at multiples of the fundamental frequency), and the variation in amplitude and frequency of each call (total range of amplitude or frequency achieved by the call). Subjects produced a low average number of vocalizations on all three time points. Generalized estimating equations accounting for the clustering 
of pups coming from the same dam (litter effects) were used to analyze the ultrasonic vocalization data. Specifically, Chi-squared tests were used to address the likelihood to call while Poisson regression was used to compare the number of vocalizations produced by cocaine, saline, and untreated groups, and linear mixed models were used to evaluate the duration of each call and acoustic spectral differences. All models adjusted for sex, group, body temperature (back or interscapular), and body weight within each $\operatorname{PND}(1,3$, or 5$)$.

Similar to the thermal data, ECG data (rate and R-R Intervals) were condensed to 10 -minute bins, and examined using repeated measures general linear models. Additionally, these data were correlated with thermal data using Pearson correlations, and compared using Fisher's r-z transformation. Cardiac weight and $\beta A R$ levels were compared between groups using two-tailed $t$-tests.

\section{RESULTS}

\section{GESTATIONAL EFFECTS}

Gestational data are detailed in Table 1. There were statistically significant differences in gestational weight gain of the dam $\left[F_{(2,54)}=7.57, p=0.001\right]$, with cocaine-treated dams gaining less weight over gestation than untreated $(p=0.001)$ and salinetreated dams $(p=0.048)$; however, cocaine-treated and saline dams gained more weight over the early postpartum period (PPDs 1-5) $\left[F_{(2,46)}=10.276, p=0.001\right]$ than untreated dams (cocaine: $p=0.001$; saline: $p=0.004$ ). There were no statistically significant differences in gestational length, total number of pups in the litter, male to female pup ratio, or pup weights on PNDs 1, 3 , or 5 .

\section{POSTNATAL DAY 1}

On postnatal day 1, pups underwent a short but severe thermal stressor $\left(25^{\circ} \mathrm{C}\right)$, during which USVs were recorded and following which the skin temperature of the pup's rump was measured. Vocalization data are presented in Figure 3. Skin temperature data are not presented, because rump temperature did not differ between treatment groups at the conclusion of testing. Not all pups vocalized on PND 1 (not significant between groups); however, among those that did vocalize, the number of calls produced during the $5 \mathrm{~min}$ challenge did not differ between groups. Additionally, pup sex and body weight were not associated with any differences in vocalization parameters. The USVs produced by cocaine pups showed a number of qualitative differences from those produced by untreated and/or saline pups. As shown in Figure 3, untreated pups produced calls with longer durations than both cocaine- $(p \leq 0.05)$ and saline-exposed pups ( $p \leq$ $0.05)$. Additionally, cocaine exposed pups produced calls with lower average peak amplitudes compared to untreated $(p \leq 0.01)$ and saline-exposed pups $(p \leq 0.05)$, and a reduced amplitude range per call compared to untreated $(p \leq 0.01)$ and salineexposed pups $(p \leq 0.05)$.

\section{POSTNATAL DAY 3}

On postnatal day 3, pups underwent a longer duration test than on postnatal day 1 , in which thermogenesis (as indicated by $T_{\mathrm{IS}}-T_{\mathrm{Back}}$ ) and concurrent USV s were assessed over a $3 \mathrm{~h}$ period across decreasing environmental temperatures. In this environment, pup body weight had a significant impact on both thermogenesis and USV production. Larger pups had significantly higher $T_{\text {IS }}(p=0.05)$ over the course of the experiment, but not $T_{\text {Back, }}$, reaffirming that heavier pups have greater thermogenic capacity. Pups that weighed more were also more likely to produce one or more USV during the experiment $(p=0.01)$, and the calls produced had lower peak frequency of the fundamental $(p=0.01)$, lower minimum frequency of the fundamental $(p=0.01)$, a greater number of harmonics per call $(p=0.01)$,

Table 1 | Gestational measures and litter characteristics following maternal cocaine or saline exposure and in untreated animals.

\begin{tabular}{|c|c|c|c|c|c|c|c|}
\hline $\begin{array}{l}\text { Treatment } \\
\text { group }\end{array}$ & $\begin{array}{l}\text { No. of } \\
\text { dams }\end{array}$ & $\begin{array}{l}\text { Gestational } \\
\text { weight gain (g) }\end{array}$ & $\begin{array}{l}\text { Postpartum } \\
\text { weight gain (g) }\end{array}$ & $\begin{array}{l}\text { No. of } \\
\text { pups }\end{array}$ & $\begin{array}{l}\text { No. of } \\
\text { male pups }\end{array}$ & $\begin{array}{l}\text { No. of } \\
\text { female pups }\end{array}$ & $\begin{array}{l}\text { Culled litter } \\
\text { weight (g) }\end{array}$ \\
\hline Cocaine & 17 & $123.5 \pm 14.5^{*}$ & $15.5 \pm 11.3^{\dagger}$ & $12.9 \pm 1.9$ & $6.5 \pm 2.1$ & $6.5 \pm 2.1$ & $60.3 \pm 6.8$ \\
\hline Saline & 17 & $139.9 \pm 24.0$ & $14.5 \pm 8.7^{\dagger}$ & $14.0 \pm 2.2$ & $6.9 \pm 1.6$ & $7.1 \pm 2.2$ & $65.7 \pm 4.1$ \\
\hline Untreated & 24 & $148.0 \pm 19.7$ & $2.1 \pm 8.6$ & $13.8 \pm 2.2$ & $6.7 \pm 1.8$ & $7.1 \pm 2.4$ & $67.7 \pm 5.5$ \\
\hline
\end{tabular}

${ }^{*}$ Cocaine group differed from Saline $(p=0.048)$ and Untreated $(p<0.001) .{ }^{\dagger}$ Cocaine $(p<0.001)$ and Saline $(p=0.004)$ differed from Untreated.
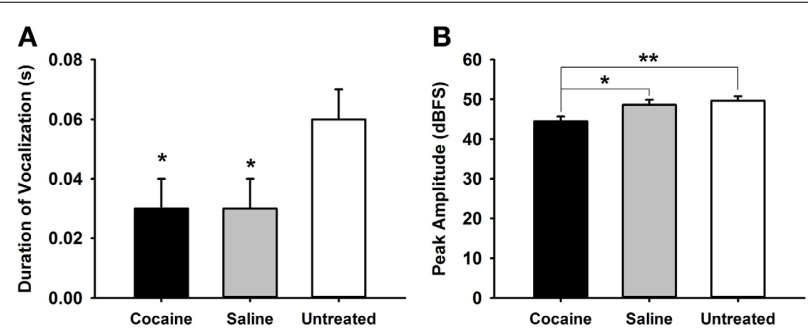

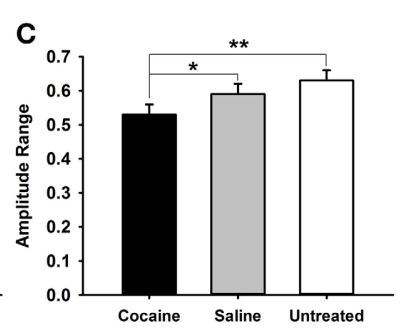

FIGURE 3 | Postnatal day 1 ultrasonic vocalizations during a $5 \mathrm{~min}$ thermal challenge. Subjects were rapidly chilled by placing them on a $25^{\circ} \mathrm{C}$ metal plate for $5 \mathrm{~min}$, during which vocalizations were recorded continuously. Pups exposed to prenatal cocaine or saline produced calls with shorter durations than untreated pups (A). Prenatal cocaine exposure also resulted in lower maximum amplitudes (B) and a smaller range of amplitudes (C) compared to both untreated and saline groups. $\left(* p \leq 0.05\right.$. $\left.{ }^{* *} p \leq 0.01\right)$. 
higher amplitude $(p \leq 0.01)$, and larger standard deviations of both frequency and amplitude $(p \leq 0.01)$. Despite the impact of weight on these parameters, and the fact that males weighed statistically more than females $(p \leq 0.01)$ on this day, males did not differ statistically from females on any USV measure.

Aside from body weight, the $T_{\text {Back }}$ of an individual pup was also strongly associated with the vocalizations produced by a pup. Pups with lower $T_{\text {Back }}$ during the experiment produced more calls ( $p \leq 0.01)$, calls with longer durations $(p \leq 0.01)$, and their calls had a larger standard deviation of frequency $(p \leq 0.01)$.

Treatment differences in thermogenesis on postnatal day 3 are presented in Figure 4. Cocaine-exposed pups had generally lower body weights on this day than untreated pups $(p \leq$ $0.05)$, but did not differ from saline-treated. Given the complex relationship between body weight, thermoregulation, and USV production described above, body weight was included in the statistical model assessing temperature differences between treatment groups. After adjusting for body weight, both cocaine- and saline-exposed pups showed higher baseline $T_{\text {IS }}(p \leq 0.05)$ and $T_{\text {Back }}(p \leq 0.01)$ temperatures compared to untreated pups (see Figure 4, insets), but not $T_{\mathrm{IS}-\mathrm{Back}}$. These raw temperature differences were maintained across all thermal challenge periods (all bins $p \leq 0.01)$. Since cocaine- and saline-exposed pups showed chronic increases in temperature across all environmental conditions, change from baseline temperature was also examined to determine if pups reacted to environmental temperatures differently despite this increase. Indeed, saline-exposed pups tended to show a reduced loss of body temperature ( $T_{\mathrm{IS}}$ and $\left.T_{\mathrm{Back}}\right)$, as would be expected by their increased body temperatures; however, cocaine-exposed pups did not maintain their body temperature to a similar extent, and instead were comparable to untreated pups in the amount of heat lost during the thermal challenges. Importantly, the difference in $T_{\text {IS }}$ and $T_{\text {Back }}$ temperatures between the groups was not due to a change in thermogenic capacity $\left(T_{\mathrm{IS}-\mathrm{Back}}\right)$. Such results may indicate that all groups were in a maximal heat producing state, and implies that variations in heat loss between groups may instead be responsible for the differences we see here.

Along with alterations in pup temperature, cocaine- and saline-exposed pups showed a myriad of effects on USVs, which are displayed in Figure 5. Many pups did not call at all during the baseline or thermal challenge periods. Only $40 \%$ of cocaine, $37 \%$ of saline, and $80 \%$ of untreated animals vocalized $\left[\chi_{(2)}^{2}=3.56\right.$, $p=0.17]$. Of those pups that did produce a call, there was no difference in the number of calls produced. However, as shown in Figure 5A, cocaine- and saline-exposed pups produced vocalizations with longer durations than untreated pups $(p \leq 0.05)$ during thermoneutral periods. Additionally, during the extreme thermal challenge cocaine-exposed pups vocalized with lowered peak frequency $(p \leq 0.05)$, lowered minimum frequency $(p \leq$ 0.01 ), and with a larger average standard deviation of frequency within a call $(p \leq 0.01)$ compared to untreated pups, but not saline-exposed pups.

\section{POSTNATAL DAY 5}

On PND 5, pups underwent a very similar experiment to the one used on postnatal day 3 , during which thermogenesis and

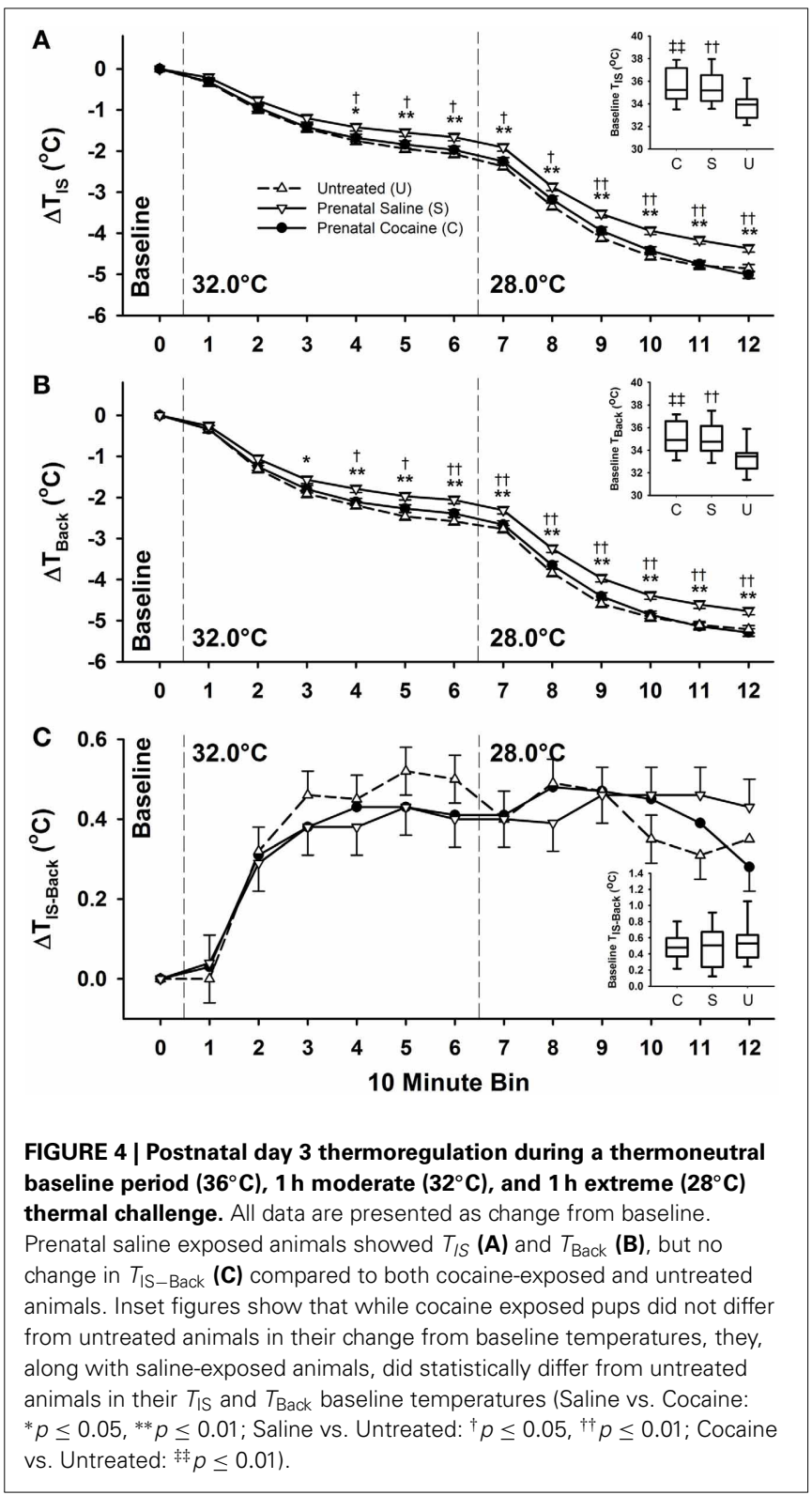

USV production were assessed over a series of thermal challenges. Again, heavier pups exhibited higher $T_{\text {IS }}(p \leq 0.01)$ and $T_{\text {IS-Back }}$ ( $p \leq 0.05)$, but not $T_{\mathrm{Back}}$ measurements, again demonstrating the greater thermogenic capacity of heavier pups. PND 5 pups with higher body weights also produced calls with longer durations, lower peak frequency of the fundamental, lower minimum frequency of the fundamental, lower fundamental frequency at loudest portion of the call, and higher peak amplitude of the call. However, the body weight difference between cocaine and untreated pups seen on PND 3 was no longer apparent on PND 5. Additionally, and as seen on PND 3, males on this day weighed more than females $(p \leq 0.01)$; however, this difference did not result in alterations in USV production.

During the thermal challenges, the rate of USV production increased as environmental temperature decreased (see Figure 6). 

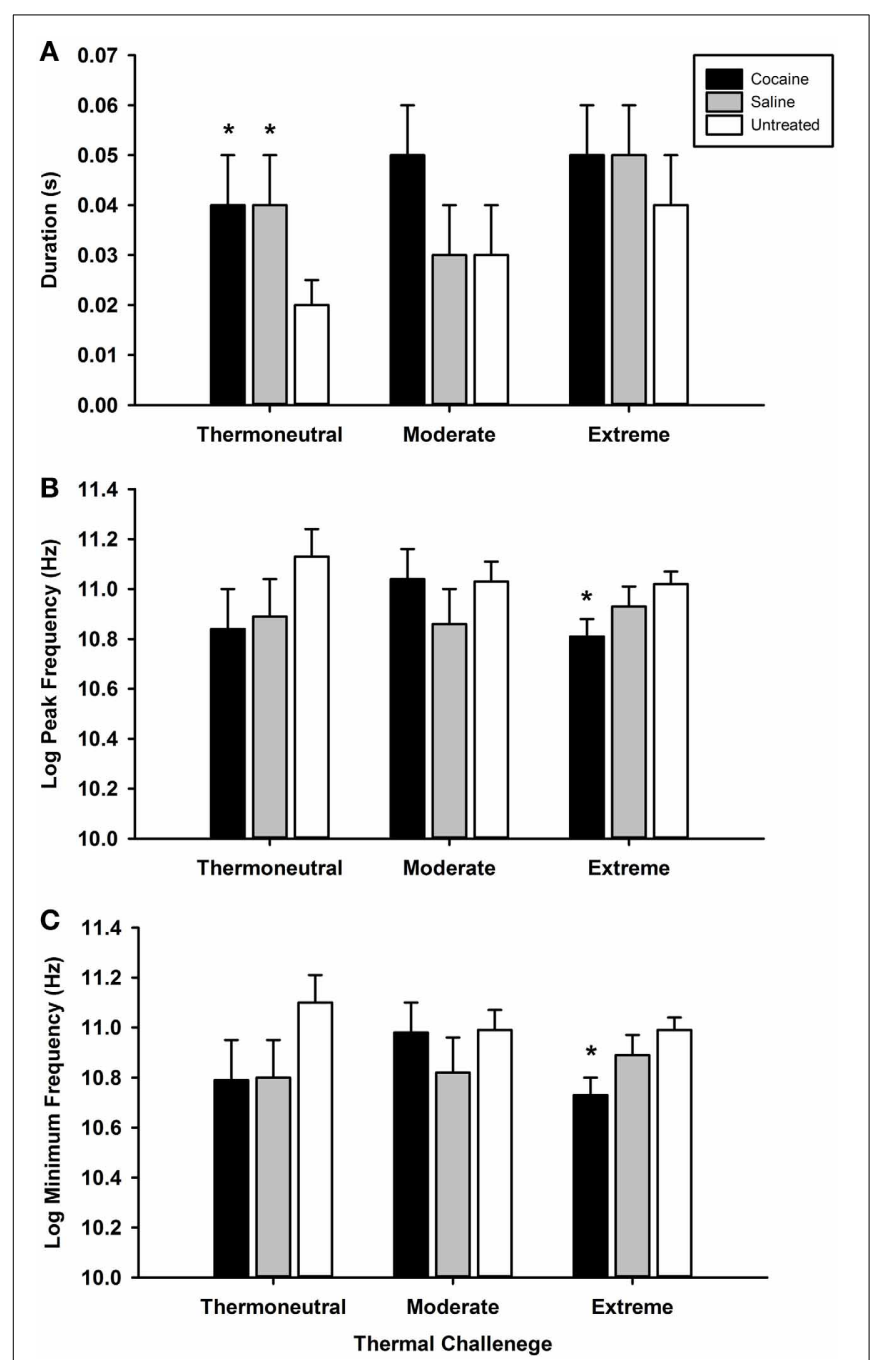

FIGURE 5 | Postnatal day 3 ultrasonic vocalization characteristics. Vocalizations were recorded during thermoneutral $\left(35^{\circ} \mathrm{C}\right)$, moderate $\left(32^{\circ} \mathrm{C}\right)$, and extreme $\left(28^{\circ} \mathrm{C}\right)$ thermal challenge periods (data averaged across each period). At this age, pups exposed to prenatal cocaine or saline demonstrated an increased average duration of each call during the thermoneutral period (A) compared to untreated animals. Additionally, cocaine exposed animals showed a reduced average maximum (B) and minimum (C) frequency per call during the extreme thermal challenge period compared to untreated animals $(* p \leq 0.05)$.

During the baseline thermoneutral period, very few calls were seen at all. Pups with higher $T_{\mathrm{Back}}$ across both thermal challenges produced fewer calls $(p \leq 0.01)$ and the calls produced had shorter durations $(p \leq 0.01)$, lower peak fundamental frequency $(p \leq 0.01)$, lower minimum fundamental frequency $(p \leq 0.01)$, lower frequency at peak amplitude of the fundamental $(p \leq$ $0.01)$, lower peak amplitude of the fundamental $(p \leq 0.01)$, and a smaller standard deviation of frequency $(p \leq 0.01)$.

As was done on PND 3, individual differences in body weight were included in the statistical model examining treatment differences in thermogenic capacity on PND 5. As shown in Figure 7 (insets), there were no baseline $T_{\mathrm{IS}}, T_{\mathrm{Back}}$, or $T_{\mathrm{IS}-\mathrm{Back}}$ differences due to prenatal cocaine or saline exposure. During the majority of the moderate thermal challenge period $\left(28.0^{\circ} \mathrm{C}\right)$ and the entire extreme $\left(21.0^{\circ} \mathrm{C}\right)$, both prenatal cocaine and saline exposure resulted in lower $T_{\mathrm{IS}}$ and $T_{\mathrm{Back}}$, compared to untreated animals (bins $5-12, p \leq 0.05$ or $p \leq 0.01$, see Figure 7 ). However, this reduction was not associated with differences in $T_{\text {IS-Back }}$. Despite the differences in $T_{\text {IS }}$ and $T_{\text {Back }}$, there was no difference in the number of calls produced between treatment groups, and no difference in any measure of call characteristics.

\section{POSTNATAL DAY 5 CARDIAC FUNCTION}

In a separate group of pups, cardiac function was assessed during and following the thermal challenges used in the above experiment on PND 5. There were no differences between males and females on any cardiac function measure. Treatment differences in cardiac function are visualized in Figure 8. Prenatal cocaine exposure was not associated with alterations in Heart Rate (data not shown), R-R Interval, R-R Variability, or cardiac $\beta A R$ levels (see Figures 8B,C,D). However, as shown in Figure 8A, cardiac mass was significantly lower in cocaine-exposed pups than in untreated pups $\left[F_{(1,127)}=8.13, p<0.01\right]$. Additionally, as shown in Figure 9, the relationship between the cardiac R-R Interval and $T_{\mathrm{IS}}$ was best fit by a 2 nd order polynomial function for both cocaine exposed $\left(r^{2}=0.95\right)$ and untreated animals $\left(r^{2}=0.98\right)$, and did not differ between treatment groups.

\section{DISCUSSION}

The data presented here demonstrate that prenatal exposure to cocaine alters measures of early postpartum thermoregulatory ability and vocalizing behavior, and that it does so similarly in both male and female rat pups, although the pattern of effects differed dynamically depending on the developmental age of the animal and the comparison control groups. There appeared to be effects attributable to perhaps stress (injection and food restriction of dams) as well as separate effects of cocaine exposure itself. These differences are important as they can help direct future mechanistic studies. Thus, here we initially discuss the effects on the saline group, followed by differences in untreated and cocaine exposed offspring. Historically, rodent studies of cocaine exposure have required comparisons to both untreated and saline/food yoked groups to control for anorectic effects of cocaine and injection stress. Results of the effects have been mixed depending on what behaviors are studied. Our inclusion of the saline control was meant to account for many of these factors; however, the pattern of effects seen in our saline-exposed offspring surprisingly differed from both our untreated control and cocaineexposed animals, especially on PND 3. On this day, saline exposed pups demonstrated baseline body temperatures almost identical to cocaine-exposed animals, but showed greater resilience in response to changes in environmental temperature (reduced change from baseline temperature). Additionally, despite differing from cocaine animals in their temperature regulation, they showed a very similar pattern of effects on vocalizing behavior, with increased call duration and mildly reduced frequency (ns).

Prenatal stress alone has been shown to have numerous effects on cardiovascular development, thermoregulation, and stress responsivity (Hashimoto et al., 2001; Mastorci et al., 2009), but 

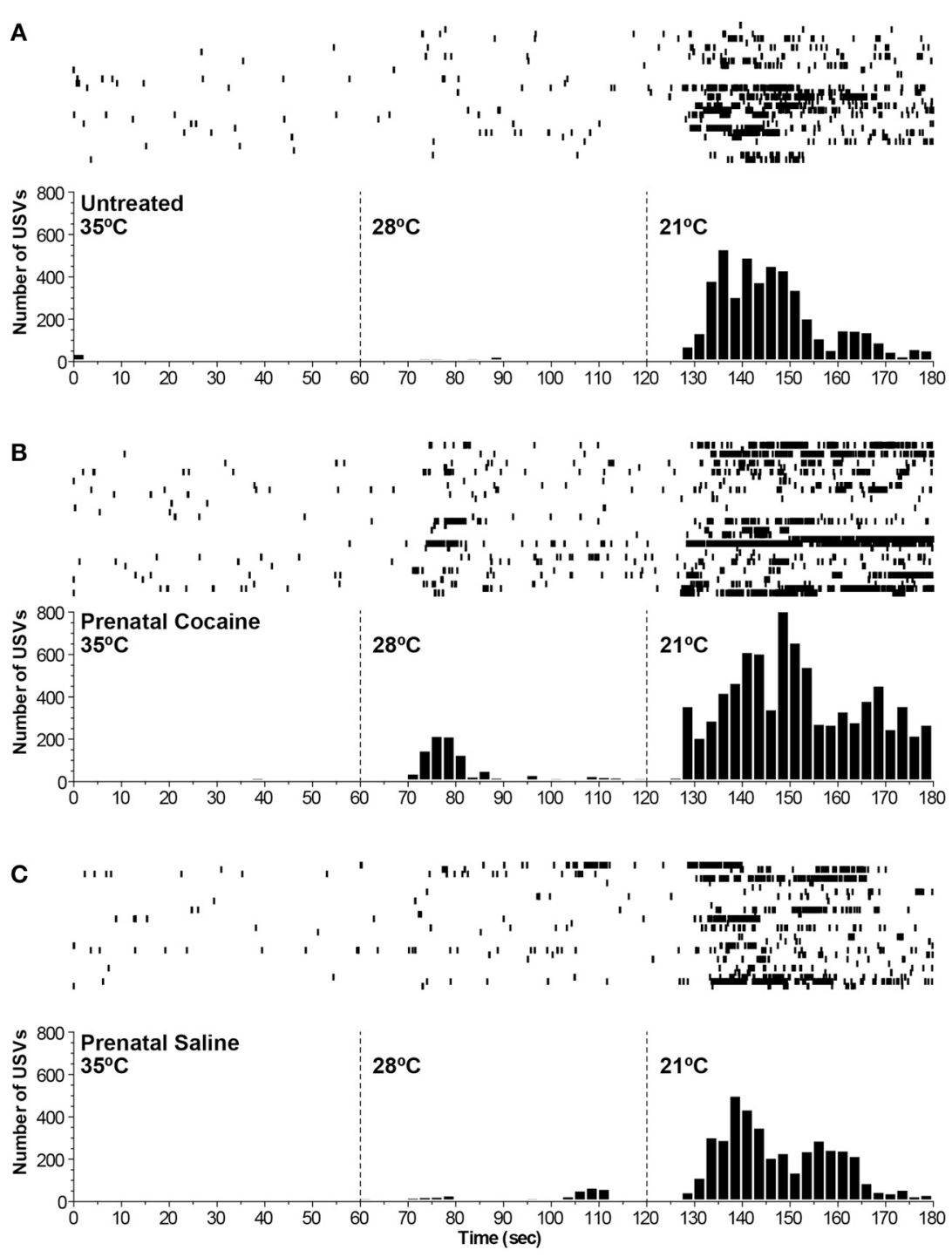

FIGURE 6 | Raster and histogram depicting the number of ultrasonic vocalizations produced by pups on postnatal day 5 across the $3 \mathrm{~h}$ thermal testing period. The first hour was at baseline thermoneutral temperature $\left(35^{\circ} \mathrm{C}\right)$, the second hour was at a moderate thermal challenge $\left(28^{\circ} \mathrm{C}\right)$, and the third hour was at an extreme thermal challenge $\left(21^{\circ} \mathrm{C}\right)$. Each line of the raster represents a single animal's vocalization pattern, with the histogram below summarizing the data across animals. All groups show relatively similar patterns of vocalizing, with the strongest increase in vocalization rates during the extreme thermal challenge. Although the cocaine (B) and saline (C) groups both show increases in vocalizing during the moderate thermal challenge period (ns), these increases appear to be driven by only a few subjects and are not seen in untreated animals (A). the degree of overlap with cocaine's effect on these measures is unknown. The obvious stress from injections may not be the sole driving factor behind these results, and is likely compounded by the stress of forced food restriction. Although not quantified in the current study, during data collection, the food restricted animals tended not to eat all the food offered, and would instead hide some throughout the cage, exhibiting a hoarding-like behavior. This unusual behavior is likely indicative of a highly stressed state. Thus, the total effect of the compounding of both stressors likely differs from the effects of cocaine, which only featured the stress of injections (reduced appetite likely differs from forced food restriction). Other studies from our own lab and others have shown similar confusing results using this and similar control groups (Wilkins et al., 1998; Johns et al., 2005; Malanga et al., 2007; McMurray et al., 2008), calling into question its usefulness in modeling these specific stress confounds.

Cocaine-exposed offspring, as compared to unexposed offspring, vocalized with shorter call durations and reduced call amplitudes on PND 1, but only 2 days later (PND 3) exhibited increased call durations and reduced frequencies, with no change in amplitude. These early differences in vocalizing behavior were not apparent by PND 5, although vocalization effects have been shown at later developmental ages (Cox et al., 2012). Clearly these important early time points in development are highly dynamic, 

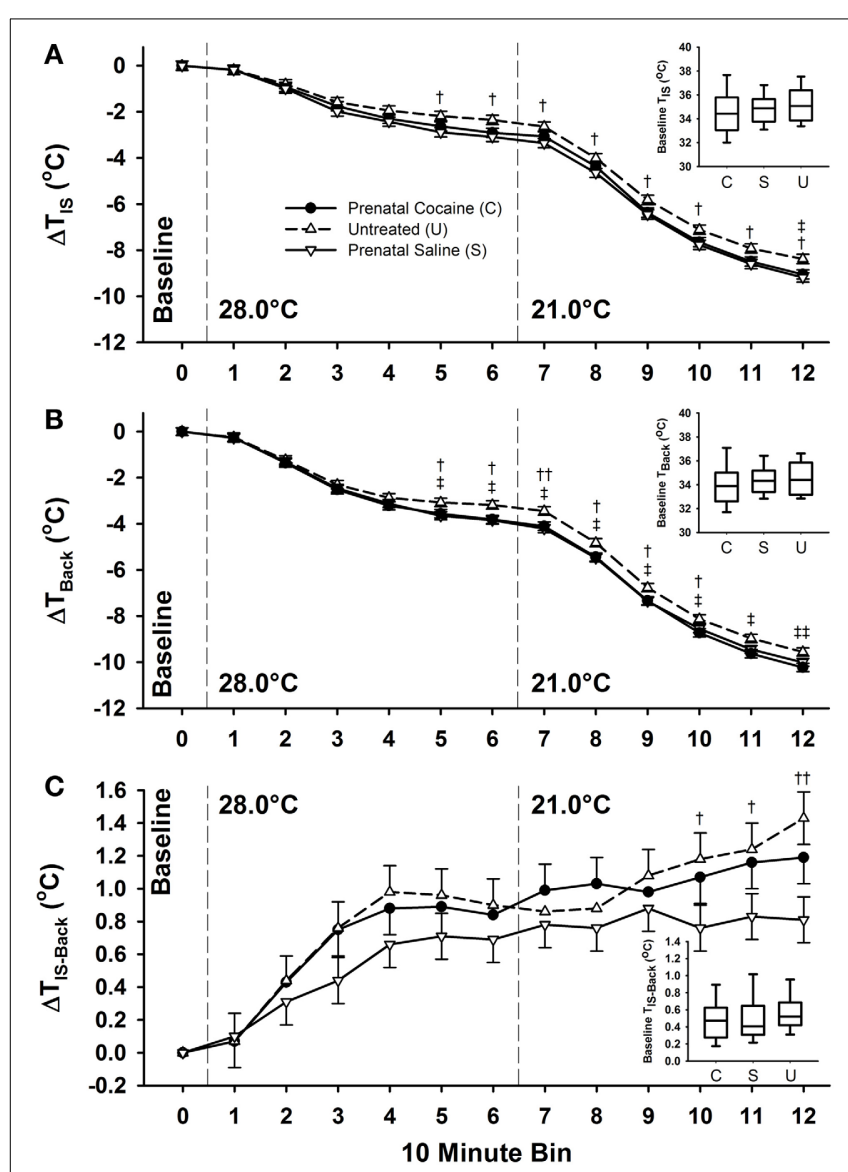

FIGURE 7 | Postnatal day 5 interscapular and back temperatures during a thermoneutral baseline period $\left(34^{\circ} \mathrm{C}\right), 1 \mathrm{~h}$ moderate $\left(28^{\circ} \mathrm{C}\right)$, and $1 \mathrm{~h}$ extreme $\left(21^{\circ} \mathrm{C}\right)$ thermal challenge. Prenatal cocaine exposure was associated with an increase in both interscapular (A) and back (B) temperatures across the later portions of the moderate challenge, and the entirety of the extreme thermal challenge, but no significant difference in $T_{\text {IS-Back }}$ (C). Additionally, there was no difference between group baseline temperatures (inset graphs). (Saline vs. Untreated: ${ }^{\dagger} p \leq 0.05,{ }^{\dagger \dagger} p \leq 0.01$; Cocaine vs. Untreated: ${ }^{\ddagger} p \leq 0.05,{ }^{\ddagger} p \leq 0.01$ ).

involving the pup's own developmental trajectories as well as social feedback from mothers and littermates. Indeed, cocaineexposed pups have been shown to receive less direct contact from dams in these very early time points, regardless of dam drug exposure (Johns et al., 2005). However, the social significance of variations in rodent USVs has yet to be fully elucidated, thus the full importance of our findings is unclear at this time.

Cocaine-exposed pups also showed differences in thermoregulatory ability. On PND 3, the vocalization differences described above were associated with an increase in baseline temperature compared to untreated controls, but no difference in change from baseline temperatures compared to untreated controls. Like the vocalization results, baseline temperature differences seemed to have resolved only two days later on PND 5; however, on that day cocaine-exposed animals did show greater change from baseline temperatures (except $T_{\text {IS-Back }}$ ). This was highly unexpected, as the typical relationship between body temperature and vocalizing

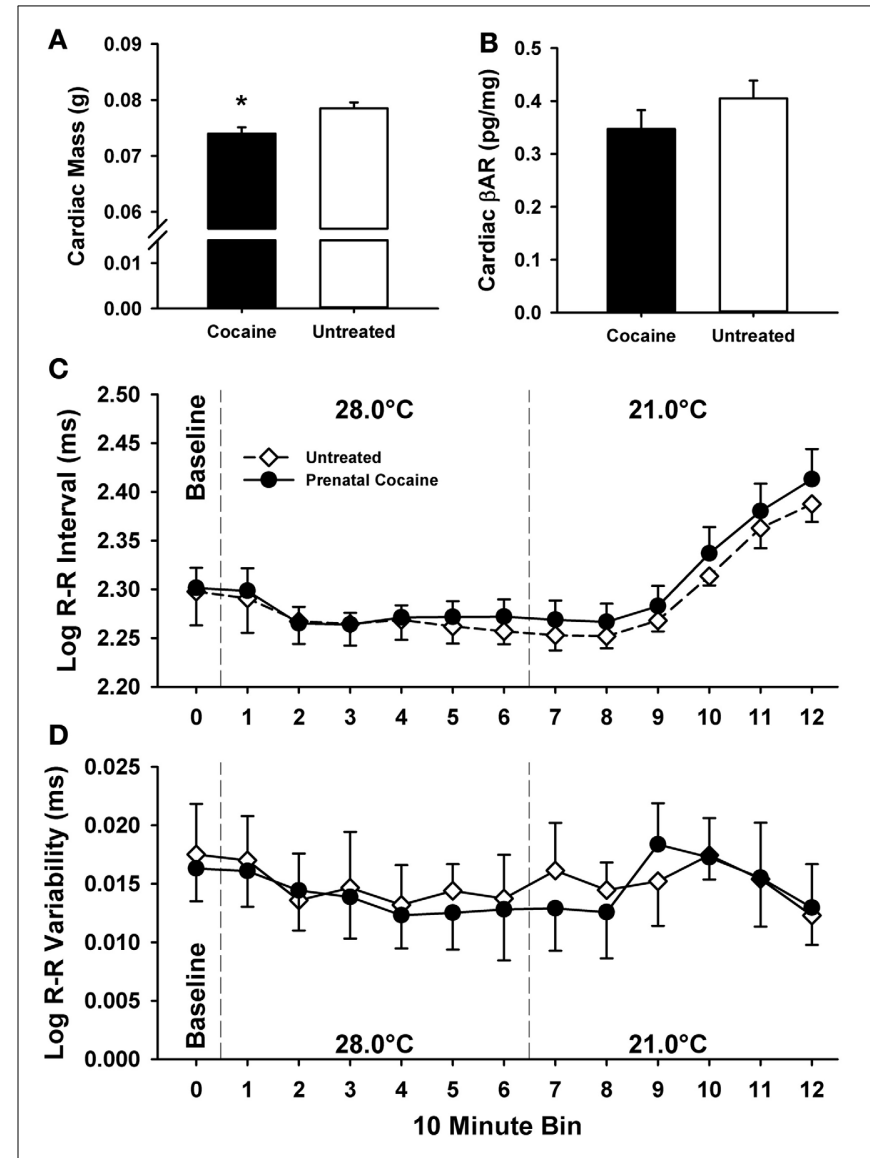

FIGURE 8 | Assessment of cardiac function on postnatal day 5 during a thermoneutral baseline period $\left(35^{\circ} \mathrm{C}\right), 1 \mathrm{~h}$ moderate $\left(28^{\circ} \mathrm{C}\right)$, and $1 \mathrm{~h}$ extreme $\left(21^{\circ} \mathbf{C}\right)$ thermal challenge. Prenatal cocaine exposure was associated with decreases in cardiac mass $(\mathbf{A})$, but no change in cardiac $\beta$-Adrenergic receptor concentrations (B) as measured following the thermal challenges. Additionally, prenatal cocaine exposure was not associated with significant change in heart rate (data not shown), R-R Interval (C), or R-R Interval Variability (D) as measured during the thermal challenges. (* $p \leq 0.05)$.

behavior would suggest that reductions in body temperature should be associated with increased vocalizing (Blumberg et al., 1992). Under this model, the reductions in body temperature seen in cocaine-exposed animals should have been associated with increased vocalizing behavior, but this was not the case.

Body temperature regulation is a relatively unstudied effect of prenatal cocaine, but the presence of such effects is not necessarily surprising given the disturbances in cardiac development previously reported (Regalado et al., 1996; Sun et al., 2003) and prior reports of acute cocaine altering thermoregulation in adults (Crandall et al., 2002). On PND 3, the baseline $T_{\mathrm{IS}}$ and $T_{\mathrm{Back}}$ of cocaine-exposed pups was almost $2^{\circ}$ (Celsius) warmer than untreated pups on average, and was maintained despite alterations in environmental temperatures. However, this result must be interpreted with caution. Both treatment groups were handled in the same manner, and given $1 \mathrm{~h}$ to acclimate to thermoneutral temperature $\left(36^{\circ} \mathrm{C}\right)$; however, the untreated pups failed to reach the same baseline temperature as the cocaine-exposed animals. 


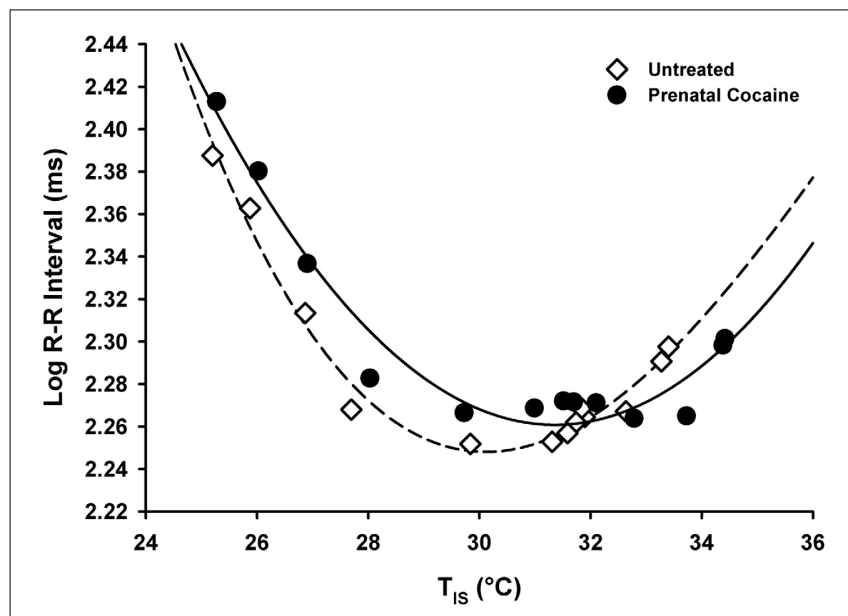

FIGURE 9 | The relationship between the cardiac R-R Interval and the interscapular temperature of the pup. Average group temperature and $\mathrm{R}-\mathrm{R}$ interval for each $10-\mathrm{min}$ bin are presented. An increasing value on the Y-axis indicates a slowing of the cardiac rate. Thus, at colder temperatures, pups tend to have reduced heart rates. Both cocaine-exposed and untreated pups show a similar relationship between these variables, with no significant difference between the two groups.

It is unclear if cocaine-exposed animals reached thermoneutrality faster, or if our untreated animals did so more slowly than is typically reported (Blumberg et al., 1997).

The pattern of thermoregulatory effects shown here would suggest non-metabolic mechanisms, and potentially point to cardiac or circulatory system effects. Although BAT is located throughout the body, the large interscapular depot of BAT, which is responsible for the delivery of warm blood to the heart and the consequent modulation of cardiac rate (Blumberg et al., 1997; Sokoloff et al., 1998), is of particular importance, as the heart acts as a pumping mechanism to distribute the heat generated by BAT throughout the body via the circulatory system. Our lack of group differences in $T_{I S-B a c k}$ (our measure of BAT thermogenesis) fit with the lack of effect on cardiac rate or R-R Intervals shown here. The startling similarity of the curves shown in Figure 9 attests to this. Instead, cardiac stroke volume, blood pressure, or other circulatory system characteristics may be more significant contributors, but were not measured here. The impact of cocaine on cardiac mass reported here, although minor, implies that stroke volume may be one of a multitude of factors contributing to the thermoregulatory effects of cocaine.

While the mechanism of the alteration in body temperature differences found on PND 3 and 5 may be unclear, this difference likely has implications for the development of other physiological systems and could be detectable by the affected pup's mother, influencing her behavior. A feedback system exists between the pup and mother, such that maternal heat is transferred to pups during close contact, but pups also act as a source of heat for mothers (Woodside and Jans, 1988). Thus, not only does a mother have incentive to isolate hyperthermic pups to reduce the body temperature of the pups, but also to reduce her own body temperature. Abnormally warm pups may offset this feedback loop in favor of reduced maternal attention and increased isolation. Indeed, cocaine-exposed pups have been shown to receive less direct contact from dams, regardless of dam drug exposure (Johns et al., 2005). In theory, the inverse relationship between these two variables (heat and maternal attention) seems in line with the thermal data reported here on PND 3, and may present a potential factor in the patterns of maternal care deficits reported earlier (Johns et al., 2005), although this was not directly tested in the present study (but should be in future work).

The strongest relationship found in our data was that the thermal state of a pup also contributes to the production of ultrasonic vocalizations in the early postnatal period; perhaps especially those vocalizations elicited by thermal mechanisms (eg laryngeal braking). The associations found here between both the weight of the pup and the temperature of the pup and its likelihood of vocalizing suggest that these calls were at least in part produced via such mechanisms. The data found here also indicate that the "body temperature" of the pup (as measured by $\left.T_{\mathrm{Back}}\right)$ also influences the sonic characteristics of the cry produced, and that this relationship changes with the age of the pup, likely reflecting a dynamic relationship between the size of the respiratory passages and the contractile force of the diaphragm.

Aside from physiological mechanisms (i.e., thermoregulation), pups may also be experiencing psychological stress related to the thermal challenge itself or resulting from isolation from littermates and their dam. In addition to the number of vocalizations produced, a number of other attributes were found to be altered by the thermal state of the pup in all treatment groups, such as the frequency, amplitude, and the variation in frequency of the call. While it is possible that such elements are the result of changes in the physiological mechanisms of vocalization production, it is also likely that such elements reflect the psychological state of the pup. Considering the ages studied here are within the "stress hypo-responsive period" (Lupien et al., 2009), such differences in mechanism might be reflected in the age-related differences between these factors in cocaine-exposed and control animals. In older animals with intact stress systems, applying psychological stress often results in vocalization production (Sánchez, 2003); however, cocaine-exposed animals may develop the necessary biological systems at different rates, leading to differences in vocalizing. Additionally, considering the stress of isolation alone can result in changed vocalization patterns (Kraebel et al., 2002; Shair et al., 2003), it is possible that the stress of isolation differs between treatment groups, which would explain our differences in vocalizations without apparent differences in thermoregulation.

In the context of the broader literature, some common themes have emerged in the study of early pup USV production, demonstrating primarily a decreased number of USVs following prenatal drug insult (Winslow and Insel, 1990; Kehoe and Shoemaker, 1991; Hahn et al., 2000; Tattoli et al., 2001; Antonelli et al., 2005) or malnutrition (Tonkiss et al., 2003). However, these studies used poorly controlled thermal environments and focused simply on the number of vocalizations emitted, thus limiting their comparability to the results presented here. Prenatal cocaine exposure in mice has been shown to increase the starting pitch of calls following a mild thermal challenge, but these effects were dependent 
upon the genotype of the subject (Hahn et al., 2000) and may not generalize to rats. Regardless, the results presented here and elsewhere (Cox et al., 2012) demonstrate a consistent pattern of altered USV production following prenatal cocaine, with effects dependent upon the age of the animal and the stimulus used to elicit vocalizations.

The data reported here must be interpreted with caution. Considering the deficits in maternal attention reported for cocaine-treated pups in the early postpartum period, without using a cross-fostered group it is difficult to separate the respective contributions of prenatal cocaine and maternal cocaine treatment. Indeed, it is likely that altered maternal care by cocaine-treated and perhaps saline-treated dams contributes to the dynamic differences in pup vocalization and thermoregulation. In order to address these issues, cross-fostering studies are needed. The PND 1 vocalization data presented here resonate with earlier cross-fostering studies showing pups with cocaine exposure elicit poor care from even untreated mothers during the very early postnatal period (Johns et al., 2005); however, the relatively low magnitude of differences we report here suggests that there are more factors involved than shown here. Other pup characteristics (such as odor) clearly play a role in determining care (Okabe et al., 2013) and need to be examined. It is probable that thermal state can also influence other pup behaviors, interacting with other cues to effectively elicit care. Additionally, it will be important to determine differences in stress-related effects aside from those attributable to cocaine treatment alone, and how these effects interact to further alter development.

\section{AUTHOR CONTRIBUTIONS}

Matthew S. McMurray provided funding, designed experiments, collected and analyzed data, and prepared the manuscript. Philip S. Zeskind assisted in experimental design, analyzed data, and provided input on manuscript. Stephanie M. Meiners assisted in experimental design, collected and analyzed data, and provided input on manuscript. Kristin A. Garber assisted in experimental design and analyzed data. Hsiao Tien analyzed data and provided input on the manuscript. Josephine M. Johns provided funding and assisted in experimental design, data analysis, and manuscript preparation.

\section{ACKNOWLEDGMENTS}

We would like to recognize the contributions of Dr. Mark Blumberg in the development of methods, data analysis, and manuscript preparation. We would also like to acknowledge Juliana Neuspiel, Caitlin Zoghby, Emily Unks, and Abigail Jamieson-Drake for their assistance in vocalization analysis, and Ben Smith and Devin Hubbard for their assistance in recording equipment design and Labview programming. Additionally, Cheryl Walker provided great assistance with the development of methods for the radioligand binding study.

\section{FUNDING}

This work was supported by the National Institute on Drug Abuse (grant numbers P01 DA022446 to Josephine M. Johns and F31 DA026251 to Matthew S. McMurray).

\section{REFERENCES}

Adels, L. E., and Leon, M. (1986). Thermal control of mother-young contact in Norway rats: factors mediating the chronic elevation of maternal temperature. Physiol. Behav. 36, 183-196. doi: 10.1016/0031-9384(86)90094-6

Alberts, J. R. (1978). Huddling by rat pups: group behavioral mechanisms of temperature regulation and energy conservation. J. Comp. Physiol. Psychol. 92, 231-245. doi: 10.1037/h0077459

Antonelli, T., Tomasini, M. C., Tattoli, M., Cassano, T., Tanganelli, S., Finetti, S., et al. (2005). Prenatal exposure to the CB1 receptor agonist WIN 55,212-2 causes learning disruption associated with impaired cortical NMDA receptor function and emotional reactivity changes in rat offspring. Cereb. cortex 15, 2013-2020. doi: 10.1093/cercor/bhi076

Bandstra, E. S., Morrow, C. E., Mansoor, E., and Accornero, V. H. (2010). Prenatal drug exposure: infant and toddler outcomes. J. Addict. Dis. 29, 245-258. doi: $10.1080 / 10550881003684871$

Bates, A., Adels, L. E., and Leon, M. (1985). Thermal control of maternal contact bouts: the interbout interval. Physiol. Behav. 34, 834-837. doi: 10.1016/00319384(85)90386-5

Blumberg, M. S., and Alberts, J. R. (1990). Ultrasonic vocalizations by rat pups in the cold: an acoustic by-product of laryngeal braking? Behav. Neurosci. 104, 808-817. doi: 10.1037/0735-7044.104.5.808

Blumberg, M. S., Efimova, I. V., and Alberts, J. R. (1992). Ultrasonic vocalizations by rat pups: the primary importance of ambient temperature and the thermal significance of contact comfort. Dev. Psychobiol. 25, 229-250. doi: $10.1002 /$ dev. 420250402

Blumberg, M. S., and Sokoloff, G. (2001). Do infant rats cry? Psychol. Rev. 108, 83-95. doi: 10.1037/0033-295X.108.1.83

Blumberg, M. S., Sokoloff, G., and Kent, K. J. (2000). A developmental analysis of clonidine's effects on cardiac rate and ultrasound production in infant rats. Dev. Psychobiol. 36, 186-193. doi: 10.1002/(SICI)10982302(200004)36:3<186::AID-DEV2>3.0.CO;2-V

Blumberg, M. S., Sokoloff, G., and Kirby, R. F. (1997). Brown fat thermogenesis and cardiac rate regulation during cold challenge in infant rats. Am. J. Physiol. 272, R1308-R1313.

Blumberg, M. S., and Stolba, M. A. (1996). Thermogenesis, myoclonic twitching, and ultrasonic vocalization in neonatal rats during moderate and extreme cold exposure. Behav. Neurosci. 110, 305-314. doi: 10.1037/0735-7044.110.2.305

Branchi, I., Santucci, D., and Alleva, E. (2001). Ultrasonic vocalisation emitted by infant rodents: a tool for assessment of neurobehavioural development. Behav. Brain Res. 125, 49-56. doi: 10.1016/S0166-4328(01)00277-7

Brouette-Lahlou, I., Vernet-Maury, E., and Vigouroux, M. (1992). Role of pups' ultrasonic calls in a particular maternal behavior in Wistar rat: pups' anogenital licking. Behav. Brain Res. 50, 147-154. doi: 10.1016/S0166-4328(05)80296-7

Brudzynski, S. M. (2005). Principles of rat communication: quantitative parameters of ultrasonic calls in rats. Behav. Genet. 35, 85-92. doi: 10.1007/s10519-0040858-3

Brunelli, S. A., Shair, H. N., and Hofer, M. A. (1994). Hypothermic vocalizations of rat pups (Rattus norvegicus) elicit and direct maternal search behavior. J. Comp. Psychol. 108, 298-303. doi: 10.1037/0735-7036.108.3.298

Chae, S.-M., and Covington, C. Y. (2009). Biobehavioral outcomes in adolescents and young adults prenatally exposed to cocaine: evidence from animal models. Biol. Res. Nurs. 10, 318-330. doi: 10.1177/1099800408330395

Champagne, F. A., Diorio, J., Sharma, S., and Meaney, M. J. (2001). Naturally occurring variations in maternal behavior in the rat are associated with differences in estrogen-inducible central oxytocin receptors. Proc. Natl. Acad. Sci. U.S.A. 98, 12736-12741. doi: 10.1073/pnas.221224598

Champagne, F. A., Weaver, I. C. G., Diorio, J., Sharma, S., and Meaney, M. J. (2003). Natural variations in maternal care are associated with estrogen receptor alpha expression and estrogen sensitivity in the medial preoptic area. Endocrinology 144, 4720-4724. doi: 10.1210/en.2003-0564

Cinti, S. (2005). The adipose organ. Prostaglandins. Leukot. Essent. Fatty Acids 73, 9-15. doi: 10.1016/j.plefa.2005.04.010

Cinti, S. (2006). The role of brown adipose tissue in human obesity. Nutr. Metab. Cardiovasc. Dis. 16, 569-574. doi: 10.1016/j.numecd.2006.07.009

Cox, E. T., Hodge, C. W., Sheikh, M. J., Abramowitz, A. C., Jones, G. F., JamiesonDrake, A. W., Makam, P. R., Zeskind, P. S., et al. (2012). Delayed developmental changes in neonatal vocalizations correlates with variations in ventral medial hypothalamus and central amygdala development in the rodent infant: effects of prenatal cocaine. Behav. Brain Res. 235, 166-175. doi: 10.1016/j.bbr.2012.07.035 
Crandall, C. G., Vongpatanasin, W., and Victor, R. G. (2002). Mechanism of cocaine-induced hyperthermia in humans. Ann. Intern. Med. 136, 785-791. doi: 10.7326/0003-4819-136-11-200206040-00006

Cypess, A. M., Lehman, S., Williams, G., Tal, I., Rodman, D., Goldfine, A. B., et al. (2009). Identification and importance of brown adipose tissue in adult humans. N. Engl. J. Med. 360, 1509-1517. doi: 10.1056/NEJMoa0810780

D'Amato, F. R., Scalera, E., Sarli, C., and Moles, A. (2005). Pups call, mothers rush: does maternal responsiveness affect the amount of ultrasonic vocalizations in mouse pups? Behav. Genet. 35, 103-112. doi: 10.1007/s10519-004-0860-9

Deviterne, D., Desor, D., and Krafft, B. (1990). Maternal behavior variations and adaptations, and pup development within litters of various sizes in Wistar rat. Dev. Psychobiol. 23, 349-360. doi: 10.1002/dev.420230406

Farrell, W. J., and Alberts, J. R. (2002a). Maternal responsiveness to infant Norway rat (Rattus norvegicus) ultrasonic vocalizations during the maternal behavior cycle and after steroid and experiential induction regimens. J. Comp. Psychol. 116, 286-296. doi: 10.1037/0735-7036.116.3.286

Farrell, W. J., and Alberts, J. R. (2002b). Stimulus control of maternal responsiveness to Norway rat (Rattus norvegicus) pup ultrasonic vocalizations. J. Comp. Psychol. 116, 297-307. doi: 10.1037/0735-7036.116.3.297

Fu, Y., Pollandt, S., Liu, J., Krishnan, B., Genzer, K., Orozco-Cabal, L., Gallagher, J. P., and Shinnick-Gallagher, P. (2007). Long-term potentiation (LTP) in the central amygdala (CeA) is enhanced after prolonged withdrawal from chronic cocaine and requires CRF1 receptors. J. Neurophysiol. 97, 937-941. doi: 10.1152/jn.00349.2006

Hahn, M. E., Benno, R. H., Schanz, N., and Phadia, E. (2000). The effects of prenatal cocaine exposure and genotype on the ultrasonic calls of infant mice. Pharmacol. Biochem. Behav. 67, 729-738. doi: 10.1016/S0091-3057(00)00418-4

Hahn, M. E., and Lavooy, M. J. (2005). A review of the methods of studies on infant ultrasound production and maternal retrieval in small rodents. Behav. Genet. 35, 31-52. doi: 10.1007/s10519-004-0854-7

Hashimoto, M., Watanabe, T., Fujioka, T., Tan, N., Yamashita, H., and Nakamura, S. (2001). Modulating effects of prenatal stress on hyperthermia induced in adult rat offspring by restraint or LPS-induced stress. Physiol. Behav. 73, 125-132. doi: 10.1016/S0031-9384(01)00473-5

Henning, S. J., and Romano, T. J. (1982). Investigation of body temperature as a possible feeding control in the suckling rat. Physiol. Behav. 28, 693-696. doi: 10.1016/0031-9384(82)90053-1

Hull, D., and Segall, M. M. (1965). Sympathetic nervous control of brown adipose tissue and heat production in the new-born rabbit. J. Physiol. 181, 458-467.

Jans, J. E., and Woodside, B. C. (1990). Nest temperature: effects on maternal behavior, pup development, and interactions with handling. Dev. Psychobiol. 23, 519-534. doi: 10.1002/dev.420230607

Johns, J. M., Elliott, D. L., Hofler, V. E., Joyner, P. W., McMurray, M. S., Jarrett, T. M., et al. (2005). Cocaine treatment and prenatal environment interact to disrupt intergenerational maternal behavior in rats. Behav. Neurosci. 119, 1605-1618. doi: 10.1037/0735-7044.119.6.1605

Johns, J. M., Nelson, C. J., Meter, K. E., Lubin, D. A., Couch, C. D., Ayers, A. A., et al. (1998). Dose-dependent effects of multiple acute cocaine injections on maternal behavior and aggression in Sprague-Dawley rats. Dev. Neurosci. 20, 525-532. doi: 10.1159/000017353

Kehoe, P., and Shoemaker, W. (1991). Opioid-dependent behaviors in infant rats: effects of prenatal exposure to ethanol. Pharmacol. Biochem. Behav. 39, 389-394. doi: 10.1016/0091-3057(91)90197-A

Kinsley, C. H., Turco, D., Bauer, A., Beverly, M., Wellman, J., and Graham, A. L. (1994). Cocaine alters the onset and maintenance of maternal behavior in lactating rats. Pharmacol. Biochem. Behav. 47, 857-864. doi: 10.1016/00913057(94)90288-7

Kodituwakku, P. W. (2009). Neurocognitive profile in children with fetal alcohol spectrum disorders. Dev. Disabil. Res. Rev. 15, 218-224. doi: 10.1002/ddrr.73

Kraebel, K. S., Brasser, S. M., Campbell, J. O., Spear, L. P., and Spear, N. E. (2002). Developmental differences in temporal patterns and potentiation of isolation-induced ultrasonic vocalizations: influence of temperature variables. Dev. Psychobiol. 40, 147-159. doi: 10.1002/dev.10022

Leon, M., Adels, L. E., and Coopersmith, R. (1985). Thermal limitation of mother-young contact in Norway rats. Dev. Psychobiol. 18, 85-105. doi: 10.1002/dev.420180202

Lévy, F., Keller, M., and Poindron, P. (2004). Olfactory regulation of maternal behavior in mammals. Horm. Behav. 46, 284-302. doi: 10.1016/j.yhbeh.2004.02.005
Lupien, S. J., McEwen, B. S., Gunnar, M. R., and Heim, C. (2009). Effects of stress throughout the lifespan on the brain, behaviour and cognition. Nat. Rev. Neurosci. 10, 434-445. doi: 10.1038/nrn2639

Madden, C. J., Tupone, D., Cano, G., and Morrison, S. F. (2013). $\alpha 2$ Adrenergic Receptor-Mediated Inhibition of Thermogenesis. J. Neurosci. 33, 2017-2028. doi: 10.1523/JNEUROSCI.4701-12.2013

Malanga, C. J., Pejchal, M., and Kosofsky, B. E. (2007). Prenatal exposure to cocaine alters the development of conditioned place-preference to cocaine in adult mice. Pharmacol. Biochem. Behav. 87, 462-471. doi: 10.1016/j.pbb.2007.06.002

Mason, G. A., Bondy, S. C., Nemeroff, C. B., Walker, C. H., and Prange, A. J. (1987). The effects of thyroid state on beta-adrenergic and serotonergic receptors in rat brain. Psychoneuroendocrinology 12, 261-270. doi: 10.1016/03064530(87)90050-3

Mason, G. A., Walker, C. H., and Little, K. Y. (1993). Effects of concurrent subchronic treatments with desmethylimipramine and propranolol on betaadrenergic and serotonin2 receptors in rat brain. Psychopharmacology (Berl). 110, 110-114. doi: 10.1007/BF02246958

Mastorci, F., Vicentini, M., Viltart, O., Manghi, M., Graiani, G., Quaini, F., et al. (2009). Long-term effects of prenatal stress: changes in adult cardiovascular regulation and sensitivity to stress. Neurosci. Biobehav. Rev. 33, 191-203. doi: 10.1016/j.neubiorev.2008.08.001

Mattson, B. J., Williams, S., Rosenblatt, J. S., and Morrell, J. I. (2001). Comparison of two positive reinforcing stimuli: pups and cocaine throughout the postpartum period. Behav. Neurosci. 115, 683-694. doi: 10.1037/0735-7044.115.3.683

Mayer, A. D., and Rosenblatt, J. S. (1998). A method for regulating the duration of pregnancy and the time of parturition in Sprague-Dawley rats (Charles River CD strain). Dev. Psychobiol. 32, 131-136. doi: 10.1002/(SICI)10982302(199803)32:2<131::AID-DEV6>3.0.CO;2-Q

McMurray, M. S., and Hubbard, D. K. (2013). A novel device for the calibration of sonic and ultrasonic recording transducers. J. Neurosci. Methods 217, 39-43. doi: 10.1016/j.jneumeth.2013.04.016

McMurray, M. S., Joyner, P. W., Middleton, C. W., Jarrett, T. M., Elliott, D. L., Black, M. A., et al. (2008). Intergenerational effects of cocaine on maternal aggressive behavior and brain oxytocin in rat dams. Stress 11, 398-410. doi: 10.1080/10253890701850239

Middlemis-Brown, J. E., Johnson, E. D., and Blumberg, M. S. (2005). Separable brainstem and forebrain contributions to ultrasonic vocalizations in infant rats. Behav. Neurosci. 119, 1111-1117. doi: 10.1037/0735-7044.119.4.1111

Mostyn, A., and Symonds, M. E. (2009). Early programming of adipose tissue function: a large-animal perspective. Proc. Nutr. Soc. 68, 393-400. doi: 10.1017/S002966510999022X

Nelson, C. J., Meter, K. E., Walker, C. H., Ayers, A. A., and Johns, J. M. (1998). A dose-response study of chronic cocaine on maternal behavior in rats. Neurotoxicol. Teratol. 20, 657-660. doi: 10.1016/S0892-0362(98)00016-6

Norman, A. L., Crocker, N., Mattson, S. N., and Riley, E. P. (2009). Neuroimaging and fetal alcohol spectrum disorders. Dev. Disabil. Res. Rev. 15, 209-217. doi: 10.1002/ddrr.72

Okabe, S., Nagasawa, M., Kihara, T., Kato, M., Harada, T., Koshida, N., et al. (2013). Pup odor and ultrasonic vocalizations synergistically stimulate maternal attention in mice. Behav. Neurosci. 127, 432-438. doi: 10.1037/a0032395

Quiñones-Jenab, V., Batel, P., Schlussman, S. D., Ho, A., and Kreek, M. J. (1997) Cocaine impairs maternal nest building in pregnant rats. Pharmacol. Biochem. Behav. 58, 1009-1013. doi: 10.1016/S0091-3057(97)00311-0

Ray, R. S., Corcoran, A. E., Brust, R. D., Kim, J. C., Richerson, G. B., Nattie, E., et al. (2011). Impaired respiratory and body temperature control upon acute serotonergic neuron inhibition. Science 333, 637-642. doi: 10.1126/science.1205295

Regalado, M. G., Schechtman, V. L., Del Angel, A. P., and Bean, X. D. (1996). Cardiac and respiratory patterns during sleep in cocaine-exposed neonates. Early Hum. Dev. 44, 187-200. doi: 10.1016/0378-3782(95)01708-9

Sánchez, C. (2003). Stress-induced vocalisation in adult animals. A valid model of anxiety? Eur. J. Pharmacol. 463, 133-143. doi: 10.1016/S0014-2999(03)01277-9

Shair, H. N., Brunelli, S. A., Masmela, J. R., Boone, E., and Hofer, M. A. (2003). Social, thermal, and temporal influences on isolation-induced and maternally potentiated ultrasonic vocalizations of rat pups. Dev. Psychobiol. 42, 206-222. doi: 10.1002/dev.10087

Shair, H. N., Masmela, J. R., Brunelli, S. A., and Hofer, M. A. (1997). Potentiation and inhibition of ultrasonic vocalization of rat pups: regulation by social cues. Dev. Psychobiol. 30, 195-200. doi: 10.1002/(SICI)10982302(199704)30:3<195::AID-DEV2>3.0.CO;2-K 
Smith, R. E. (1964). Thermoregultory and adaptive behavior of brown adipose tissue. Science (80-. ). 146, 1686-1689. doi: 10.1126/science.146.3652.1686

Smotherman, W. P., Bell, R. W., Starzec, J., Elias, J., and Zachman, T. A. (1974). Maternal responses to infant vocalizations and olfactory cues in rats and mice. Behav. Biol. 12, 55-66. doi: 10.1016/S0091-6773(74)91026-8

Sokoloff, G., Kirby, R. F., and Blumberg, M. S. (1998). Further evidence that BAT thermogenesis modulates cardiac rate in infant rats. Am. J. Physiol. 274, R1712-R1717.

Spiers, D. E., and Adair, E. R. (1986). Ontogeny of homeothermy in the immature rat: metabolic and thermal responses. J. Appl. Physiol. 60, 1190-1197.

Stern, J. M., and Lonstein, J. S. (1996). Nursing behavior in rats is impaired in a small nestbox and with hyperthermic pups. Dev. Psychobiol. 29, 101-122. doi: 10.1002/(SICI) 1098-2302(199603)29:2<101::AID-DEV2> 3.0.Co; $2-\mathrm{W}$

Strathearn, L., and Mayes, L. C. (2010). Cocaine addiction in mothers: potential effects on maternal care and infant development. Ann. N.Y. Acad. Sci. 1187, 172-183. doi: 10.1111/j.1749-6632.2009.05142.x

Sun, L. S., Takuma, S., Lui, R., and Homma, S. (2003). The effect of maternal cocaine exposure on neonatal rat cardiac function. Anesth. Analg. 97, 878-882. doi: 10.1213/01.ANE.0000074792.87311.DB

Tattoli, M., Cagiano, R., Gaetani, S., Ghiglieri, V., Giustino, A., Mereu, G., et al. (2001). Neurofunctional effects of developmental alcohol exposure in alcohol-preferring and alcohol-nonpreferring rats. Neuropsychopharmacology 24, 691-705. doi: 10.1016/S0893-133X(00)00225-6

Tonkiss, J., Bonnie, K. E., Hudson, J. L., Shultz, P. L., Duran, P., and Galler, J. R. (2003). Ultrasonic call characteristics of rat pups are altered following prenatal malnutrition. Dev. Psychobiol. 43, 90-101. doi: 10.1002/dev. 10124

Vernotica, E. M., Lisciotto, C. A., Rosenblatt, J. S., and Morrell, J. I. (1996). Cocaine transiently impairs maternal behavior in the rat. Behav. Neurosci. 110, 315-323. doi: 10.1037/0735-7044.110.2.315

Vernotica, E. M., Rosenblatt, J. S., and Morrell, J. I. (1999). Microinfusion of cocaine into the medial preoptic area or nucleus accumbens transiently impairs maternal behavior in the rat. Behav. Neurosci. 113, 377-390. doi: 10.1037/07357044.113.2.377
Wilkins, A. S., Genova, L. M., Posten, W., and Kosofsky, B. E. (1998). Transplacental cocaine exposure. 1: a rodent model. Neurotoxicol. Teratol. 20, 215-226. doi: 10.1016/S0892-0362(97)00125-6

Winslow, J. T., and Insel, T. R. (1990). Serotonergic modulation of rat pup ultrasonic vocal development: studies with 3,4-methylenedioxymethamphetamine. J. Pharmacol. Exp. Ther. 254, 212-220.

Woodside, B. C., and Jans, J. E. (1988). Neuroendocrine basis of thermally regulated maternal responses to young in the rat. Psychoneuroendocrinology 13, 79-98. doi: 10.1016/0306-4530(88)90008-X

Yee, N., Plassmann, K., and Fuchs, E. (2011). Juvenile stress impairs body temperature regulation and augments anticipatory stress-induced hyperthermia responses in rats. Physiol. Behav. 104, 408-416. doi: 10.1016/j.physbeh.2011.04.036

Zimmerberg, B., Kim, J. H., Davidson, A. N., and Rosenthal, A. J. (2003). Early deprivation alters the vocalization behavior of neonates directing maternal attention in a rat model of child neglect. Ann. N.Y. Acad. Sci. 1008, 308-313. doi: 10.1196/annals.1301.039

Conflict of Interest Statement: The authors declare that the research was conducted in the absence of any commercial or financial relationships that could be construed as a potential conflict of interest.

Received: 08 August 2013; paper pending published: 10 October 2013; accepted: 05 November 2013; published online: 26 November 2013.

Citation: McMurray MS, Zeskind PS, Meiners SM, Garber KA, Tien H and Johns JM (2013) Effect of prenatal cocaine on early postnatal thermoregulation and ultrasonic vocalization production. Front. Psychol. 4:882. doi: 10.3389/fpsyg.2013.00882

This article was submitted to Cognition, a section of the journal Frontiers in Psychology.

Copyright (C) 2013 McMurray, Zeskind, Meiners, Garber, Tien and Johns. This is an open-access article distributed under the terms of the Creative Commons Attribution License (CC BY). The use, distribution or reproduction in other forums is permitted, provided the original author(s) or licensor are credited and that the original publication in this journal is cited, in accordance with accepted academic practice. No use, distribution or reproduction is permitted which does not comply with these terms. 